\title{
Research of Professional Education for Aviation Equipment Support Based on CBL Instruction Method
}

\author{
Zheng Wang ${ }^{a}$, Jianhua Song, Xingdong Zhu, Jiali Fan \\ Naval Aviation Engineering Institute-Qingdao Branch, Qingdao China \\ aw_zheng@public.qd.sd.cn
}

\begin{abstract}
Keywords: CBL, Military professional education, Aviation equipment support professional, Teaching Reform.
\end{abstract}

\begin{abstract}
Military professional education, which is a kind of job-oriented education after Diploma education, has become the main task of military colleges and universities. CBL (Case-based Learning) teaching is a typical case-based discussion teaching model. Its characteristic can meet the needs of aeronautical equipment support professional education. By focusing on their representation, professionalism and operability, the typical teaching cases should be screened and optimized firstly, and then make meticulous instructional design and classroom design. Simultaneously the teaching effectiveness should be evaluated objectively to improve the teaching quality.
\end{abstract}

\section{Introduction}

With the Expansion of mission space and tasks and accelerating of military modernization construction, the military occupation of the post of military personnel competency have become increasingly demanding. Solely relying on academic education can not meet the needs of national defense modernization. Under this condition, the military professional education as a post education, special vocational job training, was becoming more important. Continue to strengthen and optimize the education and training of military tenure, increase teaching methods, teaching content, teaching management reform, and effectively improve the representation of education and training education teaching effect, the smooth realization of the military institutions of higher learning educational transformation was an important issue. Aviation equipment support personnel are the talent base for supporting the equipment's battle Effectiveness. due to aviation equipment being high-tech equipment, so the ability demand for support men are higher, this needing to adopt more effective teaching methods to achieve the implementation of education for their appointment.

\section{Current drawbacks of military professional education and training}

The purpose of professional education is to serve the demand for jobs by updating knowledge, skills training, quality training, etc., to expand the professional knowledge of students, enhance students' vocational skills, to improve the overall quality of students, so as to better qualified professional and technical posts ${ }^{1-2}$. With the modernization of our army now accelerating and deepening, Army Position Education has substituted academic education, and it becoming the main task of our military education institutions of higher learning. For a long time, academic education has been the military's main mission of education and universities, institutions and colleges and universities teaching faculty therefore widespread tendency to light heavy academic education office education ${ }^{3}$.Often the teaching content and teaching methods of teaching qualifications or even do a simple modification applied without modification serving education, lack of relevance and purpose, can not meet the actual needs of the training participants, this is an important problem to be solved serving education and training.

Army Post Education students completing higher education is the basis of education, to adapt to the post office and the gradual promotion of professional education needs and carried out, in terms of teaching objects, teaching purposes and teaching methods are very different and academic education. The main emphasis is academic education "three bases" teaching, so that students have a solid 
theoretical background, never their future into the workplace on the basis of the need for self-learning and knowledge expansion basis. Post Education students participating in itself have received systematic study of knowledge, already have professional background, we are from the actual troop line of work, with practical experience. Serving the purpose of education stronger, greater demand for practical knowledge and skills, which emphasize the teaching focus is no longer "Three Basics" training, but the emphasis on training students the ability to identify and solve practical problems, and update their knowledge structure, and effectively improve the quality and level of their business.

In the teaching process, We investigate and analysis the student's school office educating youth motivation and training needs through a variety of methods of questionnaires and discussion exchanges. The results showed that students generally strong motivation, training and learning expectations by increasing the interpersonal and improve their own quality and professional level; the demand for teaching content, students focus on "ways and means to acquire knowledge" and "solve practical issues" policy; bias in case-based teaching methods, discussion teaching, and teachers understand the force requirements, the ability to combine theory and practical force for effective teaching. Visible, constantly optimize the teaching methods and content, and effectively improve teaching effectiveness and student satisfaction is an important challenge facing education reform office.

\section{The characteristics of CBL teaching being suitable for professional Education of Aviation Equipment Support Training}

CBL (Case-based Learning) and PBL (Problem-based Learning) is an internationally more popular two teaching methods in recent years, with the deepening of education reform, many colleges learn advanced teaching experience, the introduction of two class teaching methods to improve the quality of teaching. The CBL and PBL are discussion teaching, but both there are some differences in ideas and teaching methods. PBL teaching is a method of problem-pilot, student-centered, teacher observers, it stimulating students' self-curiosity maximally. There are essential difference between this teaching method and domestic traditional teaching method. the most prominent feature of this method is the teacher losing a strong dominant, from the knowledge of "communicators" to "observers". The success of teaching depends on the individual student self-learning ability and effort, and the degree of difficulty of teaching content availability. The characteristics of PBL determine the scope of its application, not all levels, the nature of the students can carry out PBL teaching. Some investigation shows that for many professional and student levels, strengths and not get to play the role of PBL in teaching, teaching effect is not significant as expected .CBL method is a new method developing based on PBL, which is characterized by teachers and students need to share responsibility, and explore issues through prepared to guide students finding and solving problems. Its core idea lays emphasis on "boot". In practice, a typical case for the pilot, according to the syllabus and the students' practical level, teachers play the role as the leading bilateral activities and student-centered, teachers need to make a thorough tutorial design, organize students analyzed and discussed. In this pedagogy, always carry out teachers guide students how to find and solve problems. CBL teaching with both teachers play a "knowledge provider" leading role and students' active thinking and learning the dominant position, so that the two can be a good interaction, both full play the initiative of students, improve student participation and learning achievement and ensures the opportunity to teachers to impart knowledge and experience, enable students to master more accessible and professional knowledge and skills to achieve the desired effect of teaching .CBL characteristics make it very suitable for the teaching profession, office education, enabling students to fully grasp "Get knowledge of the ways and means "to discover and develop their ability to solve practical problems, improve the professional level, to meet the training needs of students.

The subject of Aviation equipment support is an emphasizing practical application discipline, especially for professional education, with emphasis on the ability to train students to discover and resolve support issues of aviation equipment. From past experience and information mastered by communicating with students, the participants usually were not familiar with actual conduct aviation 
equipment maintenance, troubleshooting aviation equipment, aviation equipment maintenance and other specific characteristics of actual equipment support work, which is most needed ability and knowledge in the actual work. CBL teaching provides a new ideas and new methods to further improve the effectiveness of training education office, especially for the military aviation equipment support science and other disciplines strong practical usefulness, especially for its educational purposes.

\section{The implementation of CBL teaching in Aviation Equipment Support Professional Education and Training and noted issues}

Screening and optimization of CBL teaching cases. Firstly, summarize learn professional skills and knowledge points according to the characteristics of aviation equipment maintenance, troubleshooting aviation equipment and aviation equipment maintenance, screen the typical case of education and training, and then by teaching experienced teachers and some students representatives of exchanges and communication, to evaluate their representation, professionalism and operability, thus ensuring both cases screened more common and typical in grassroots units, can cause students interest and sympathy, but also to maximize the application professional knowledge and skills, the ability to effectively make students get business training.

Organization and practice of CBL teaching. For selected cases, teaching purposes and the actual situation of students to make careful design and classroom teaching design, arrange teaching contents carefully, and carefully comprehend the practical implementation of CBL classroom teaching, organizing students to carry out a detailed analysis of the case and active discussion, play students active thinking and active participation to experience and personally to address practical problems, while arranged homework, let alone the students to complete a specific job, the job is completed for the participants to conduct reviews, to truly grasp solve such the ability to practical problems. Adopt comprehensive, three-dimensional interactive teaching mode, the military science, management, equipment support and other expert teachers teach the same stage cases by teacher-student interaction, student interaction, so that students become the protagonist of the classroom, changing from passive acceptance active participation, greatly stimulating interest in learning and enthusiasm equipment support personnel, the ability to exercise all kinds of logistical support staff to analyze and solve problems. In addition, the active role of the network teaching platform, the use of the "Forum", "Frequently Asked Questions", "Information Resources" and other sections of the case and guide students to discuss hot issues, questions and self-learning.

Investigation, evaluation and analysis of CBL teaching effectiveness. After teaching all over the course, by using knowledge, skills examination, questionnaires, face to face communication and other forms to evaluate the CBL teaching examination results, the degree of students recognition and satisfaction, comprehensive evaluation of teaching effectiveness. Examination should be "teaching and testing separation" principle, the instructor does not participate in the papers and papers reviewers proposition, assessment is divided into theoretical knowledge examination and professional skills assessment, the proportion of $50 \%$ each. At the same time the use of questionnaires, discussion exchange and other forms of organized student self-assessment and discussion of individual evaluation during training and learning motivation, interest and self-efficacy, and the instructor, teaching and evaluation methods for secret selection, encourage them to comment and recommendations.

Summary and optimization of CBL teaching. After the end of the course instruction and effectiveness evaluation, the item such as content organization, classroom teaching process, the specific implementation details and operation, examination should be carefully summarized, attention should be paid to opinions and suggestions of the participants to reflect objectively evaluate the effectiveness of CBL teaching, analyzing problems and deficiencies which exist, and the corresponding improvement strategies and measures should be proposed to continuously improve application effect CBL teaching. 


\section{References}

[1] Xiaoyong Xiao,Yulin Luo. Overall Transformation and Innovation of Military Professional Education [J]. Continuing Education Research. 2012(5): 34-35.

[2] Cheng Zhang, Jiang Wang, Shishun Zhu. Research of basic problem for military academies professional education. Curriculum Construction. [J]. Academy of military transportation, 2012, 14(7): 70-71.

[3] Yonghong Yu, Wanjun Li, Qiang Wang. Reflections on Professional Teaching of military instructors. [J]. Reading and writing magazine.2012,9(2):70-71. 